\title{
Association between B7-H1 and cervical cancer: B7-H1 impairs the immune response in human cervical cancer cells
}

\author{
JIANYING TAO* , JIANRONG DAI ${ }^{*}$ and SHUNYU HOU \\ Department of Gynecology and Obstetrics, The Affiliated Suzhou Hospital of \\ Nanjing Medical University, Suzhou, Jiangsu 215006, P.R. China
}

Received December 16, 2015; Accepted March 10, 2017

DOI: $10.3892 /$ etm.2017.5100

\begin{abstract}
The aim of the present study was to determine the preliminary mechanism of action of B7 homolog 1 (B7-H1) and investigate the association between $\mathrm{B} 7-\mathrm{H} 1$ and cervical cancer. The expression of B7 family proteins was measured in cervical cancer cells. Cervical cancer cells were co-cultured with T lymphocytes. An ELISA assay was subsequently conducted to analyze cytokine concentrations in the supernatants of the cultured T cells in cervical cancer cells and B7-H1 downregulated cells. Levels of interleukin (IL)-1 $\beta$, IL-6 and tumor necrosis factor- $\alpha$ mRNA in mice injected with cervical cancer cells or B7-H1 downregulated cells were measured by reverse transcription-quantitative polymerase chain reaction. It was determined that cervical cancer cells express high levels of B7-H1, whereas the normal cervical epithelium does not express B7-H1. When co-cultured with T lymphocytes, cervical cancer cells were involved in the inhibition of lymphocyte activation. When B7-H1 was downregulated using a lentivirus, the proliferation ability did not change compared with cervical cancer cells, whereas the soluble factors secreted by $\mathrm{T}$ cells differed between cervical cancer cells and B7-H1 downregulated cells. In an animal model, injected B7-H1 downregulated cervical cancer cells elicited a more intense immune response, whereas cervical cancer cells had the wild immune response. Therefore, the results of the present study demonstrate that B7-H1 mediates the low immunogenicity of cervical cancer and is not attacked by the immune system.
\end{abstract}

\section{Introduction}

The cervix is often referred to as the uterus gate, due to the fact that it functions as a defense and guard. Due to the special

Correspondence to: Dr Shunyu Hou, Department of Gynecology and Obstetrics, The Affiliated Suzhou Hospital of Nanjing Medical University, 26 Daoqian Road, Suzhou, Jiangsu 215006, P.R. China E-mail: hou_shunyu@sina.com

"Contributed equally

Key words: cervical cancer, B7-H1, immune escape status of the uterine cervix, it is vulnerable to attack from external bacteria and viruses. Unique morphological changes occurring in the cervical epithelial tissue that comprises the cervical epithelium may result in malignant transformation or inflammation (1). Cervical cancer is the fourth most common type of cancer and the fourth most common cause of cancer-associated mortality in women worldwide $(2,3)$. There are different types. of cervical cancer: About $90 \%$ of all cervical cancer cases are squamous cell carcinomas, $\sim 10 \%$ are adenocarcinomas and a small proportion of cases are other types, including small cell carcinoma and clear cell carcinoma (4). Recently, the number of cervical cancer cases detected in younger women (women aged 45 years or younger is defined as here) has increased from 18.02/100,000 in 2012 to $19.71 / 100,000$ in 2013 (5). Tumors occur as the result of a number of factors, including a weakening of the body's immune system, exposure to chemical carcinogenic factors, physical carcinogenic factors or biological carcinogenic factors and a variety of chronic stimulation (6).

Current treatment for cervical cancer consists of a combination of surgery, radiotherapy and chemotherapy (7) and the five-year survival rate for patients with cervical cancer in the United States is $68 \%$, which is a high 5-year survival rate compared with pancreatic cancer or lung cancer (8). Outcomes, however, depend heavily on how early the cancer is detected. It has been reported that the cervical cancer microenvironment often has low levels of T cell immunity, which is important as $\mathrm{T}$ cell immunity serves a vital role in recognizing and inhibiting the growth and proliferation of tumor cells (9).

B7 homolog 1 (B7-H1) is a recently identified family of B7 co-stimulatory molecules that serve an important role in inhibiting $\mathrm{T}$ cell activation and promoting $\mathrm{T}$ cell apoptosis (10). It has been reported that B7-H1 is exploited by tumors to evade immune responses (11). In many different types of human cancer, B7-H1 is expressed on the cell surface and a correlation between its expression and poor clinical prognosis has been identified in gastric, renal, breast, ovarian and esophageal carcinoma (12-16). A number of studies have investigated the association between $\mathrm{B} 7-\mathrm{H} 4$ and cervical cancer (17-19). However, few studies have focused on the role of the B7-H1 molecule in cervical cancer. The present study attempted to identify the association between B7-H1 and cervical cancer, and the role B7-H1 serves in the immune regulation of cervical cancer. 
A total of 12 specimens of cervical cancer tissue were investigated in the present study and using immunohistochemistry, it was determined that they all expressed B7-H1. However, immunohistochemistry indicated that normal cervical epithelium taken from healthy controls was negative for B7-H1. It has been demonstrated that cervical cancer cells can inhibit the activation of $\mathrm{T}$ lymphocytes (17). However, following the downregulation of B7-H1 expression using specific blocking antibodies, suppression of $\mathrm{T}$ lymphocytes was inhibited. When B7-H1 was downregulated using a lentivirus carrying a small interfering RNA (siRNA) specific for B7-H1, the ratio of human cervical cancer cells (the green fluorescent protein ratio in mice injected with green fluorescent protein cancer cells) was decreased, whereas the immune response was increased. Therefore, the results of the present study suggest that B7-H1 may be developed as a novel target for the gene therapy of cervical cancer.

\section{Materials and methods}

Ethics statement. All methods were performed in accordance with the approved guidelines. In the present study, samples were collected with the written consent of subjects and the written approval of the Ethical Review Board of the Suzhou Hospital, Affiliated with Nanjing Medical University (Suzhou, China). Mice used in the present study were handled in strict accordance with the appropriate animal practices. All experimental procedures using mice in the present study were reviewed and approved by the Ethical Review Board of Nanjing Medical University.

Isolation and culture of normal cervical epithelium and cervical cancer cells. A total of 27 patients were studied in the present study. From these 27 patients, 15 normal cervical epithelial samples (from 15 female patinents with hysteromyoma aged 45 years or younger who had undergone routine womb excision) and 12 cervical cancer samples were obtained (from 12 female patients with cervical cancer aged 45 or younger who had undergone colposcopy and biopsy of the suspicious cancerous area and pathological diagnosis to confirm cervical cancer) at Suzhou Hospital, which is Affiliated with Nanjing Medical University (Suzhou, China), between September 2015 to September 2016. Normal cervical epithelial and cervical cancer cell samples were isolated by a two-step combined dissociation method using dispase and trypsin prior to being plated into a $10-\mathrm{cm}$ culture dish (Corning Inc., Corning, NY, USA) and expanded (20). The cells were cultured in keratinocyte serum-free medium (Invitrogen; Thermo Fisher Scientific, Inc., Waltham, MA, USA) in a humidified incubator in $5 \% \mathrm{CO}_{2}$ at $37^{\circ} \mathrm{C}$ and were passaged by trypsinization $(0.25 \%$ trypsin, $0.1 \%$ EDTA $)$ and expanded serially with a split ratio of 1:3 at $80 \%$ confluence after 10 days. Cells were maintained in a humidified incubator in $5 \% \mathrm{CO}_{2}$ at $37^{\circ} \mathrm{C}$ for $\sim 1$ week. In the present study, all procedures were performed following the guidelines established by Suzhou Hospital-Affiliated Nanjing Medical University Ethics Boards and written approval was granted from the Ethical Review Board of Suzhou Hospital. Written consent was obtained from all women, after they were informed that the samples would be used for study purposes.
$R N A$ isolation and reverse transcription-quantitative polymerase chain reaction ( $R T-q P C R)$. Total RNA was isolated using the RNeasy Mini extraction kit (Qiagen, Inc., Valencia, CA, USA) according to the manufacturer's instructions. A total of $1 \mu \mathrm{g}$ RNA was used for reverse transcription and cDNA was synthesized from total RNA following the manufacturer's instructions (Qiagen, Inc.). For qPCR, primer mixes were loaded in duplicate wells in 96-well plates and PCR was performed following the addition of SYBR Green PCR Master mix (Thermo Fisher Scientific, Inc.) and $1 \mu \mathrm{g}$ (final) cDNA. The following thermocycling conditions were applied: Pre-denaturation at $95^{\circ} \mathrm{C}$ for $5 \mathrm{~min}$; followed by 40 cycles of denaturation for $15 \mathrm{sec}$ at $95^{\circ} \mathrm{C}$; and annealing and elongation at $65^{\circ} \mathrm{C}$ for $35 \mathrm{sec}$. (Bio-Rad Laboratories, Inc., Hercules, CA, USA). As an internal control, GAPDH levels were quantified in parallel with target genes. Relative quantification of the target was determined by the $2^{-\Delta \Delta \mathrm{Cq}}$ method (21). The primers used were as follows: B7-H1 forward, 5'-TGGCATTTGCTGAACGCA TTT-3' and reverse, 5'-TGCAGCCAGGTCTAATTGTTTT-3'; B7-H2 forward, 5'-TGGCATTTGCTGAACGCATTT-3' and reverse, 5'-AAAGTTGCATTCCAGGGTCAC-3'; B7-H3 forward, 5'-CCCACAGGTTGCTTTGCTTAA-3' and reverse, 5'-GCAGACCCCTGGAGAACCA-3'; B7-H4 forward, 5'-TCT GGGCATCCCAAGTTGAC-3' and reverse, 5'-TCCGCCTTT TGATCTCCGATT-3'; interleukin (IL)-1 $\beta$ forward, 5'-TTC AGGCAGGCAGTATCACTC-3' and reverse, 5'-GAAGGT CCACGGGAAAGACAC-3'; IL-6 forward, 5'-CTGCAAGAG ACTTCCATCCAG-3' and reverse, 5'-AGTGGTATAGAC AGGTCTGTTGG-3'; tumor necrosis factor (TNF)- $\alpha$ forward, 5'-CAGGCGGTGCCTATGTCTC-3' and reverse, 5'-CGATCA CCCCGAAGTTCAGTAG-3'; GAPDH forward, 5'-AGAAGG CTGGGGCTCATTTG-3' and reverse, 5'-AGGGGCCATCCA CAGTCTTC-3'.

Flow cytometry analysis. The expression of cell surface antigens on cervical cancer cells was analyzed by flow cytometry. A total of $2 \times 10^{5}$ cells were detached by trypsin and re-suspended in phosphate-buffered saline (PBS) containing $1 \%$ bovine serum albumin. They were then counted using a hemocytometer and $2 \times 10^{5}$ cells were incubated at $37^{\circ} \mathrm{C}$ for 30 min with diluted pre-immune immunoglobulin (Ig) $\mathrm{G}$ to block nonspecific binding of the antibodies (22). Following incubation at $4^{\circ} \mathrm{C}$ for $1 \mathrm{~h}$ with a primary antibody specific for B7-H1 (cat. no. ab210931, dilution 1:100; Abcam, Cambridge, UK), the cells were washed three times in PBS. Cells were then incubated with phycoerythrin (PE)-labeled goat anti-mouse IgG secondary antibody (cat. no. ab5881, dilution 1:100; Abcam) at $37^{\circ} \mathrm{C}$ for $1 \mathrm{~h}$. Negative controls were conducted by performing incubation without primary antibodies. The results were analyzed using a FACSCalibur $^{\mathrm{TM}}$ flow cytometer (BD Biosciences, Franklin Lakes, NJ, USA). All data were analyzed using FlowJo 7.2.2 software (Tree Star Inc, Ashland, OR, USA), following recently updated guidelines (23).

Histological and immunochemical analysis. Cervical cancer tissue from human patients and mice, respectively were immediately fixed at room temperature in $4 \%$ paraformaldehyde for $24 \mathrm{~h}$ and were subsequently embedded in paraffin. Consequently, $5-\mu \mathrm{m}$ thick paraffin sections were 
evaluated using, immunohistochemistry and the light microscope (magnification, x20) was used to evaluate staining. Mouse anti-human B7-H1 monoclonal antibody (cat. no. ab210931, dilution 1:100; Abcam) was used for immunohistochemistry. Immunohistochemistry was performed according to the indirect streptavidin-biotin-peroxidase method (24). For immunostaining, the samples were incubated with a PE-conjugated secondary antibody (cat. no. ab5881, dilution 1:100; Abcam) and then counterstained with DAPI (Southern Biotech, Birmingham, AL, USA) and observed under a fluorescence microscope (magnification, x10; Leica DM 2500; Leica Microsystems, Inc., Buffalo Grove, IL, USA).

Preparation of peripheral blood mononuclear cells (PBMCs) to obtain T lymphocytes. Whole blood collected from healthy adult donors was provided by the Suzhou Red Cross Blood Center (Suzhou, China). PBMCs were isolated from blood using Ficoll-Biocoll Separation Solution (Jingyang, Tianjin, China), as previously described (25). PBMCs were added to RPMI-1640 medium (Hyclone, Logan, UT, USA) and centrifuged at $\sim 600 \mathrm{x} \mathrm{g}$ for $5 \mathrm{~min}$ at room temperature. The supernatant was discarded, cells were resuspended in RPMI-1640 medium and counted using a light microscope. PBMCs were seeded in triplicate at $2 \times 10^{5}$ cells/well in 96-well plates and incubated at $37^{\circ} \mathrm{C}$ for 3 days in a humidified $5 \% \mathrm{CO}_{2}$ environment.

T lymphocyte proliferation assay. To assess the various effects of cervical cancer cells and the normal cervical epithelium on $\mathrm{T}$ cell proliferation, both types of cells were treated with $10 \mu \mathrm{g} / \mathrm{ml}$ mitomycin C (Sigma-Aldrich; Merck kGaA, Darmstadt, Germany) for $2 \mathrm{~h}$ at $37^{\circ} \mathrm{C}$. For the proliferation assay, $2 \times 10^{4}$ cervical cancer cells/well and normal cervical epithelium were plated in triplicate into 96-well plates, respectively. T lymphocytes were stimulated using $0.4 \mu \mathrm{g} / \mathrm{ml}$ anti-human cluster of differentiation CD3 (cat. no. 10977-H001, dilution 1:100; BD Pharmingen; BD Biosciences) and CD28 antibodies (cat. no. 560684, dilution 1:100; BD Pharmingen; BD Biosciences). The ratios of $\mathrm{T}$ cells to cervical cancer cell or normal cervical epithelium were both 5:1. Cell proliferation was measured at 48 and $72 \mathrm{~h}$ independently following incubation using the Cell Counting Kit-8 (CCK-8) (Takara Biotechnology Co., Ltd., Dalian, China) assay.

Infection. Green fluorescent protein (GFP)-positive cervical cancer cells and B7H1-downregulated GFP positive cervical cancer cells were constructed. A lentivirus containing the GFP gene (LV-EGFP) was obtained from Stemcell Technologies, Inc. (Shanghai, China). Lentivirus containing the GFP gene and interfering RNA for B7H1 downregulation were constructed using the same vector. A total of $2 \times 10^{5}$ cells were seeded and then added $1.3 \times 10^{6} \mathrm{IU} / \mathrm{ml}$ of lentivirus with $10 \mathrm{mg} / \mathrm{ml}$ polybrene. After $24 \mathrm{~h}$ at $37^{\circ} \mathrm{C}$, the medium was changed, the cells were cultured in a humidified incubator in $5 \% \mathrm{CO}_{2}$ at $37^{\circ} \mathrm{C}$. The culture medium was consisted of $90 \%$ Dulbecco's modified Eagle's medium (Hyclone) and $10 \%$ fetal bovine serum (Invitrogen; Thermo Fisher Scientific, Inc.). When the cervical cancer cells and B7H1 downregulated cervical cancer cells were $\sim 80 \%$ confluent, GFP-positive cells were detected using a flow cytometer (BD Biosciences).
MTT assay. B7H1 downregulated cervical cancer cells and cervical cancer cells were seeded in 96-well culture plates at an optimal density of $5 \times 10^{3}$ cells/well in triplicate wells (15). Following incubation at $37^{\circ} \mathrm{C}$ for $0,24,48,72,96$ and $120 \mathrm{~h}$, the cells were stained with $20 \mu \mathrm{l} \mathrm{MTT}(5 \mathrm{mg} / \mathrm{ml})$ at $37^{\circ} \mathrm{C}$ for $4 \mathrm{~h}$ and subsequently solubilized with $150 \mathrm{ml}$ dimethyl sulfoxide. Absorbance was measured at $490 \mathrm{~nm}$ using a microtitration plate spectrophotometer and calculated using GraphPad Prism 5 software (GraphPad Software, Inc., La Jolla, CA, USA). Cell growth curves were calculated as the mean values of each group.

Immunofluorescence. Slides (Nalgene Nunc International, Naperville, IL, USA) that were 5- $\mu \mathrm{m}$ thick were obtained via frozen section at $-20^{\circ} \mathrm{C}$ were washed twice in PBS and fixed in acetone for $5 \mathrm{~min}$. Cells were blocked for $30 \mathrm{~min}$ in 3\% BSA (Sigma-Aldrich; Merck kGaA) in PBS. Nuclei were counterstained with 4',6-diamindino-2-phenylindole-2 (Sigma-Aldrich; Merck KGaA) for $3 \mathrm{~min}$ at room temperature. Preparations were observed under a fluorescence microscope (magnification, x10; Leica DM 2500; Leica Microsystems, Inc.).

ELISA assay. The ELISA reagents for interferon (IFN)- $\gamma$ (cat. no. RAB0223), IL-10 (cat. no. RAB0244) and transforming growth factor (TGF)- $\beta 1$ (cat. no. RAB0460) were all purchased from Sigma-Aldrich (Merck kGaA). Experiments were performed according to the manufacturer's instructions. Supernatants were collected from the $\mathrm{T}$ cells of the cervical cancer cells and B7-H1 downregulated cells. The cells were cultured for 12, 24 and $48 \mathrm{~h}$. The experiments were processed as triplicate samples and the analysis was completed using a Bio-Tek ELX800 microplate reader at $450 \mathrm{~nm}$ (Bio-Tek Instruments, Inc., Winnoski, VT, USA).

Animal model. A total of $20 \mathrm{BALB} / \mathrm{c}$ female mice (weigh, 25-30 g; age, 4 weeks old) were obtained from the Chinese Academy of Sciences (Beijing, China). The temperature of the housing room was $22^{\circ} \mathrm{C}$, with $60 \%$ humidity. Mice had free access to food and water every day and were observed for 5 weeks. Mice were housed individually and observed every day. Mice were randomly divided into 2 groups $(n=10$ per group). Briefly, $40 \mathrm{mg} / \mathrm{kg}$ nembutal (Sigma-Aldrich; Merck $\mathrm{kGaA}$ ) was used to anesthetize mice. A total of $2 \times 10^{10} / 1$ GFP-positive cervical cancer cells or $2 \times 10^{10} / 1 \mathrm{~B} 7-\mathrm{H} 1$ downregulated cells were hypodermically injected into 10 mice. The end-point of the experiment was 35 days, which meant that days the mice were sacrificed and the samples were obtained at days 30 and 35. Subsequently, mice were sacrificed via overdose using $80 \mathrm{mg} / \mathrm{kg}$ nembutal intraperitoneal injection. Both $\mathrm{B} 7 \mathrm{H} 1$ downregulated cervical cancer cell and cervical cancer cell tumors in mice experienced the following treatment: Fixing, frozen section and the images were captured of GFP cells using a fluorescent microscope. Both tumor samples were digested into single cells and the GFP ratio was measured by flow cytometry. Furthermore, the expression levels of IL-1 $\beta$, IL- 6 and TNF- $\alpha$ in both tumor samples, were analyzed using mouse specific primers. The detail methods involved in animal experiment were described in the previous sections. 
A

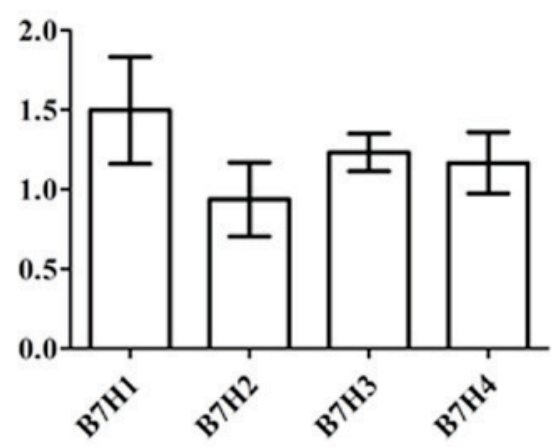

C

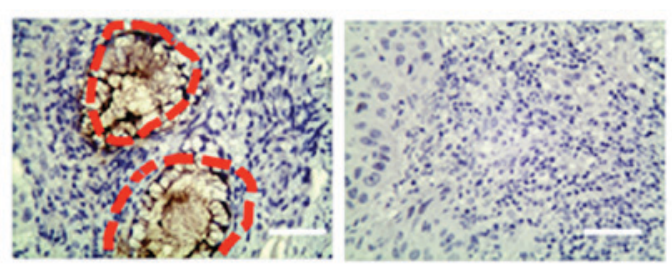

B

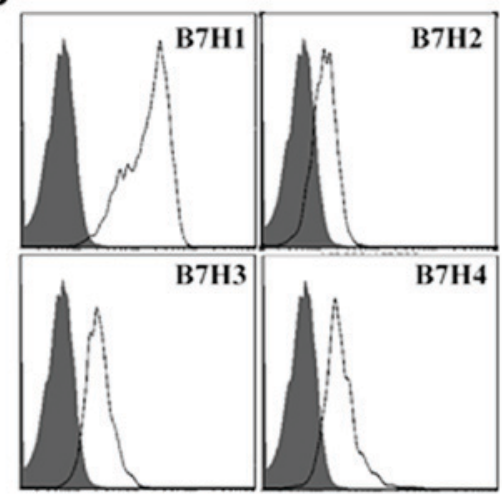

D

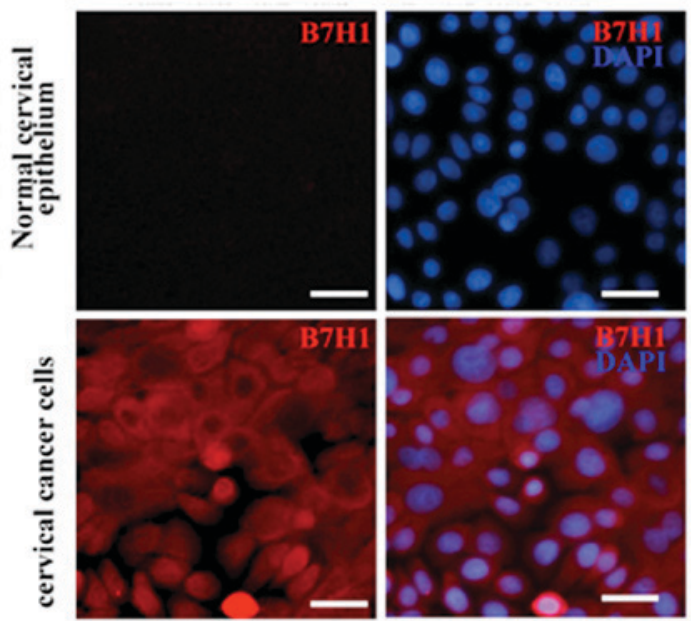

Figure 1. High expression of B7-H1 in cervical cancer cells and tissue. (A) mRNA expression levels of B7-H1, B7-H2, B7-H3 and B7-H4 in cervical cancer cells. (B) Levels of B7-H1, B7-H2, B7-H3 and B7-H4 protein in cervical cancer cells. (C) Immunohistochemistry results indicated that B7-H1 was highly expressed in cervical cancer cells (right-hand side; indicated by the red dotted-lined circles). However, no B7-H1 expression was observed in paracancerous tissue or normal cervical tissue (left-hand side; magnification, x10). (D) Immunostaining of B7-H1 (red) in normal cervical epithelium and cervical cancer cells. Nuclei (blue) were stained with 4',6-diamindino-2-phenylindole-2 (magnification, x20). Scale bar, $40 \mu \mathrm{m}$. B7-H, B7 homolog.

Statistical analysis. Data were presented as the mean \pm standard deviation of at least three independent experiments and analyzed using Prism 5 software (Graph Pad Software, Inc., La Jolla, CA, USA). Differences between each group were analyzed using one-way analysis of variance and the Dunnett's post hoc test. $\mathrm{P}<0.05$ was considered to indicate a statistically significant difference.

\section{Results}

Expression of B7-H1 in cervical cancer cells. To assess the expression of the B7 family of negative co-stimulatory molecules in cervical cancer, cervical cancer cells were studied. As presented in Fig. 1A, cervical cancer cells expressed the negative co-stimulatory molecules B7-H1, B7-H2, B7-H3 and B7-H4, of which, expression of B7-H1 was the highest. Results from flow cytometry indicated that in cervical cancer cells, B7-H1 protein was expressed at higher levels compared with B7H2, B7H3 or B7H4 (Fig. 1B). Thus, the present study focused on B7-H1. The expressions of B7-H1 in the 12 cervical cancer samples were measured using immunohistochemistry. The results demonstrated that B7-H1 was highly expressed in patients with cervical cancer (inside the red cycle; Fig. 1C), whereas B7-H1 was not expressed in paracancerous tissue and normal cervical tissue. In addition to the cancer tissue, immunostaining demonstrated that the cervical cancer cells expressed B7-H1. Conversely, the normal cervical epithelium was negative for B7-H1 expression (Fig. 1D).

The role of B7-H1 in the inhibitory effect of cervical cancer cells on human lymphocytes. To investigate the role of B7-H1 in the inhibitory effect of the immune response to $\mathrm{T}$ cells, cervical cancer cells were co-cultured with human T lymphocytes. CD3 was also used to stimulate the activation of T lymphocytes. Mitomycin-treated cervical cancer cells inhibited the activity of $\mathrm{T}$ lymphocytes, whereas normal cervical epithelial tissue did not have any marked inhibitory effects (Fig. 2). Following the use of the specific blocking antibodies of B7-H1 and siRNA to downregulate the expression of B7-H1, and specific blocking antibodies of B7-H3 to downregulate the expression of $\mathrm{B} 7-\mathrm{H} 3$, it was demonstrated that the B7-H1 blocking antibody and siRNA are able to inhibit the suppression of $\mathrm{T}$ lymphocytes by cervical cancer cells to a greater extent than the B7-H3 blocking antibody. 
A

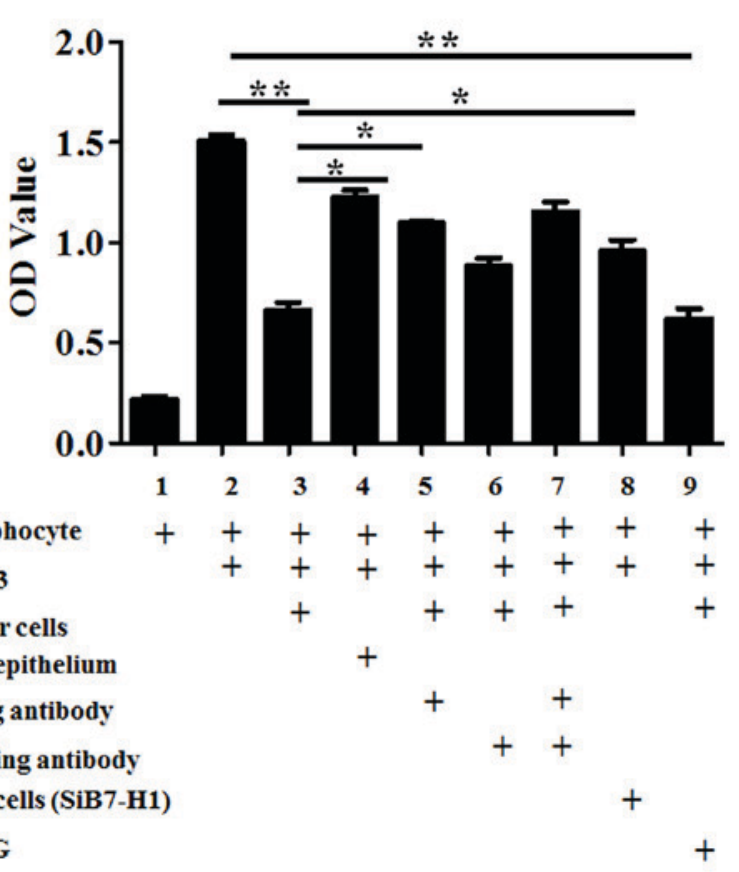

B
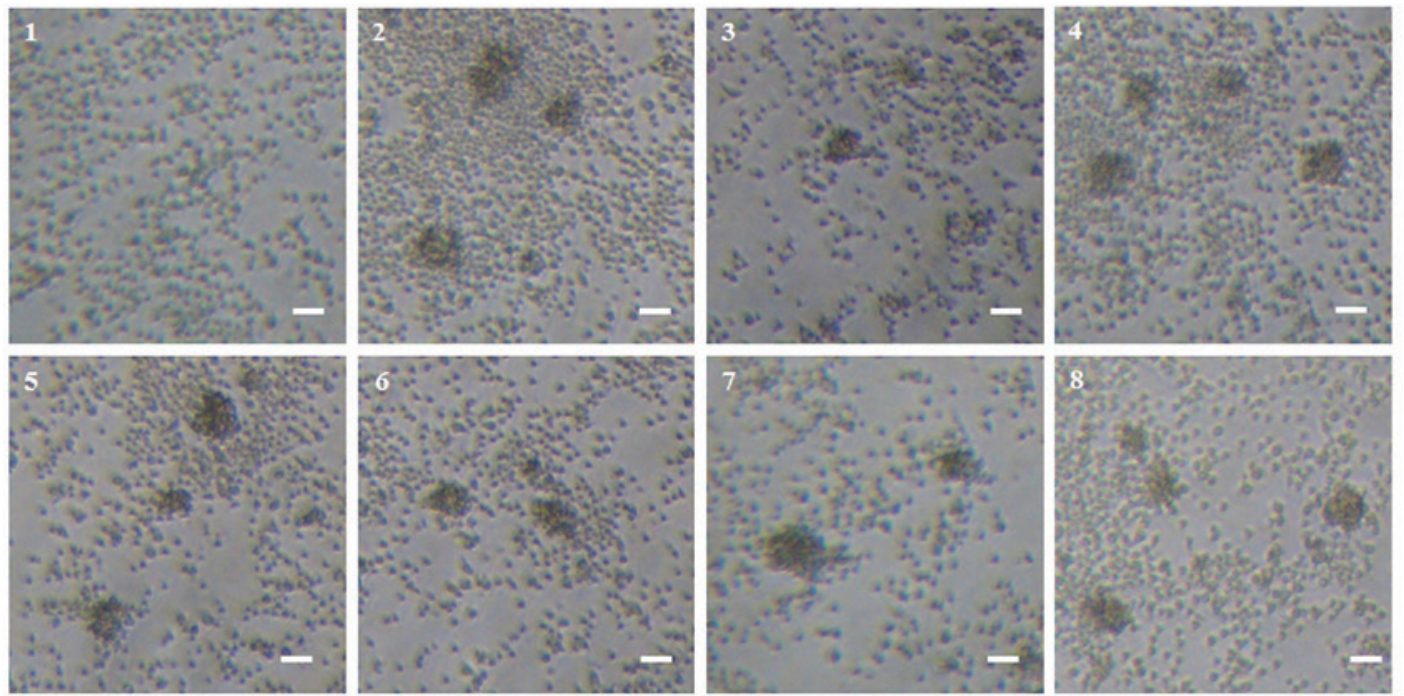

Figure 2. Downregulation of B7-H1 in cervical cancer suppresses the inhibitory ability of cervical cancer cells on human T lymphocytes. (A) Analysis of the inhibitory effect of cervical cancer cells on human lymphocytes and the effect of the B7 family blocking antibody on the inhibitory ability of cervical cancer cells. Cell Counting Kit- 8 data are presented as the mean \pm standard deviation of 3 independent experiments. Analysis was performed with GraphPad Prism; ${ }^{*} \mathrm{P}<0.05 ;{ }^{* *} \mathrm{P}<0.01$. (B) The corresponding cell images: 1 , T lymphocyte; 2 , T lymphocyte + CD3; 3, T lymphocyte + CD3 + cervical cancer cells; 4, T lymphocyte + CD3 + normal cervical epithelium; 5 , T lymphocyte + CD3 + cervical cancer cells + B7-H1 blocking antibody; 6 , T lymphocyte + CD3 + cervical cancer cells + B7-H3 blocking antibody; 7, T lymphocyte + CD3 + cervical cancer cells + B7-H1 blocking antibody + B7-H3 blocking antibody. 8, T lymphocyte + CD3 + B7-H1 downregulated (SiB7-H1) cervical cancer cells (magnification, x10). Scale bar, $40 \mu \mathrm{m}$. CD, cluster of differentiation; B7-H, B7 homolog; OD, optical density; Ig, immunoglobulin.

Furthermore, B7-H1 and B7-H3 combined did not exert a significantly greater effect than B7-H1 or B7-H3 alone (Fig. 2; cells represented by each bar are shown in figure legend). It was therefore concluded that B7-H1 is an important molecule in inhibiting the immune response in cervical cancer cells.

The role of $\mathrm{B} 7-\mathrm{H} 1$ in the proliferation and cytokine secretion by $T$ cell of cervical cancer cells. The results from ELISA demonstrated that following co-culture with $\mathrm{T}$ cells, the concentration of IFN- $\gamma$ in the B7-H1 downregulated group increased slightly following $12 \mathrm{~h}$ co-culture. At 24 and $48 \mathrm{~h}$, the concentration gradually increased and at $48 \mathrm{~h}$ was significantly higher in the $\mathrm{B} 7-\mathrm{H} 1$ group compared with the control $(\mathrm{P}<0.05)$. However, IL-10 and TGF- $\beta 1$ secretion was significantly lower than in the cervical cancer cell group at all time points measured ( $\mathrm{P}<0.05$; Fig. $3 \mathrm{~A})$. B7-H1 is associated with a number of tumor-infiltrating $\mathrm{CD} 8^{+} \mathrm{T}$ lymphocytes and therefore increases IFN- $\gamma$ production (26). 
A
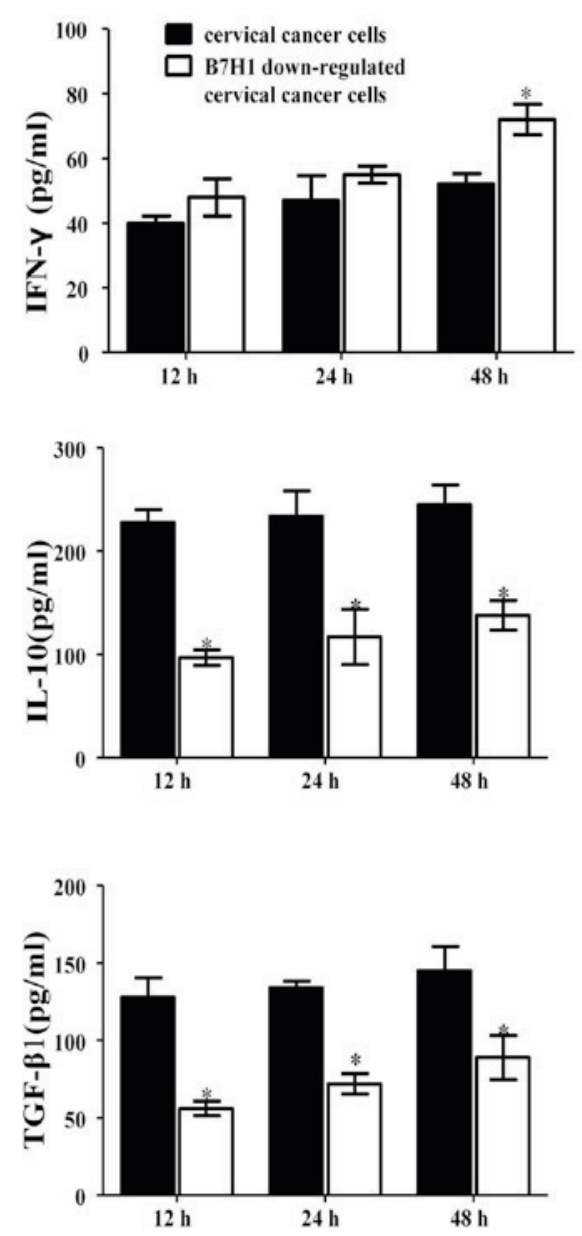

B
$\rightarrow$ cervical cancer cells
$\bullet$ B7H1 downregulated cervical cancer cells

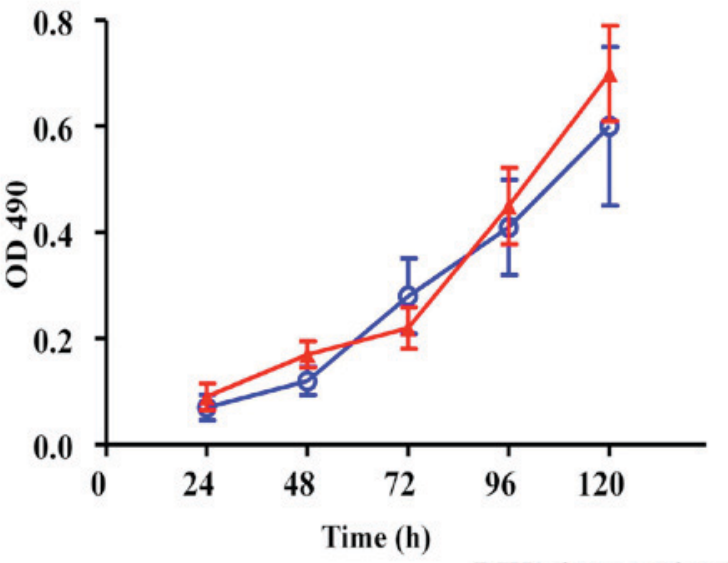

C cervical cancer cells B7H1 downregulated
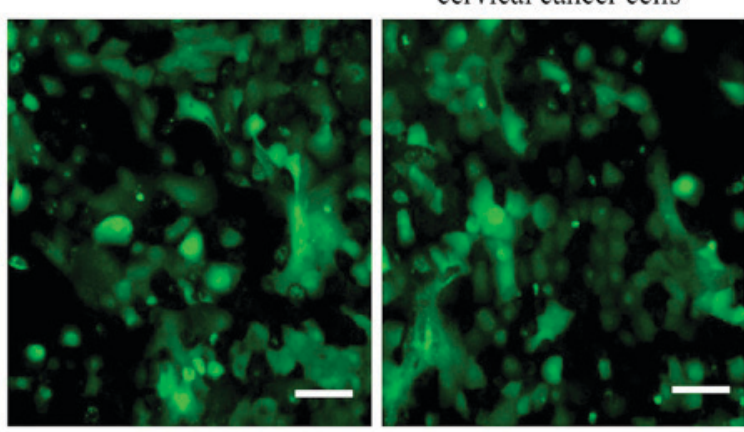

Figure 3. The role of B7-H1 in the viability and cytokine secretion by T cell of cervical cancer cells. (A) ELISA results indicating cytokine concentrations in the supernatants of the cultured T cells from cervical cancer cells and B7-H1 downregulated cervical cancer cells group after 12, 24 and 48 h. Analysis was performed with GraphPad Prism. "P $<0.05$. (B) MTT assay demonstrated the viability of cervical cancer cells and B7-H1 downregulated cervical cancer cells. Analysis was performed using GraphPad Prism. "P<0.05. (C) A GFP reporter gene was delivered into cervical cancer cells and B7-H1 downregulated cervical cancer cells using a lentiviral vector. Immunofluorescence showed that almost $100 \%$ of the cells were GFP positive (magnification, x10). Scale bar, $40 \mu \mathrm{m}$. B7-H, B7 homolog; GFP, green fluorescent protein; IL, interleukin; IFN, interferon; TGF, transforming growth factor; OD, optical density.

Results from the MTT assay demonstrated that when B7-H1 was downregulated in cervical cancer cells, cell viability was the same as in cervical cancer cells, which implies that the proliferation ability of both types of cells did not differ significantly (Fig. 3B). To further investigate the underlying mechanism, a GFP reporter gene was introduced into cervical cancer cells and B7-H1 downregulated cervical cancer cells using a lentiviral vector. These cells were then injected into BALB/c nude mice. Immunofluorescence showed that almost $100 \%$ of the cells were GFP positive, confirming the credibility of the following experiment (Fig. 3C). The aforementioned results suggested that when these two types of cells (B7H1 downregulated cervical cancer cells and cervical cancer cells) were transplanted into the subcutis of BALB/c nude mice, the difference in the ability to resist immune rejection was only influenced by the B7H1 downregulated cervical cancer cells and cervical cancer cells.

In the present study, the delitescence period of tumor formation was $\sim 4$ weeks. To observe the proportion of GFP-positive cells engrafted into the mice, the tumor and surrounding normal tissue were excised. Results from immunofluorescence staining indicated that the cervical cancer cell group had a larger number of GFP-positive cells than the B7-H1 downregulated cervical cancer cell group on days 30 and 35 (Fig. 4A). Flow cytometry analysis indicated that the proportion of GFP-positive cells in the cervical cancer cell group was $~ 25 \%$ on day 30 , with this proportion increasing to $\sim 36 \%$ on day 35 . Conversely, the proportion of GFP-positive cells in the B7-H1 downregulated cervical cancer cell group was $\sim 12 \%$ on day 30 and declined to $\sim 3 \%$ by day 35 (Fig. 4B). Additionally, tissue from cervical cancer cells and B7-H1 downregulated cells with the surrounding precancerous lesions were excised and dispersed into a single-cell suspension, respectively. The expression of IL- $1 \beta$, IL- 6 and TNF- $\alpha$ was then analyzed using mouse specific primers. As presented in Fig. $4 \mathrm{C}$, the expression of IL- $1 \beta$ in cervical cancer cells was significantly lower than in the B7-H1 downregulated cervical cancer cells on the first day $(\mathrm{P}<0.05)$. On day 14 , the expression of IL-1 $\beta$ in B7-H1 downregulated cervical cancer cells reached a peak. A similar pattern was observed regarding the significant difference in expression of IL- 6 on day 1 and TNF- $\alpha$ on day $7(\mathrm{P}<0.05)$. This indicates that B7-H1 aids the evasion of tumors from the immune system. 


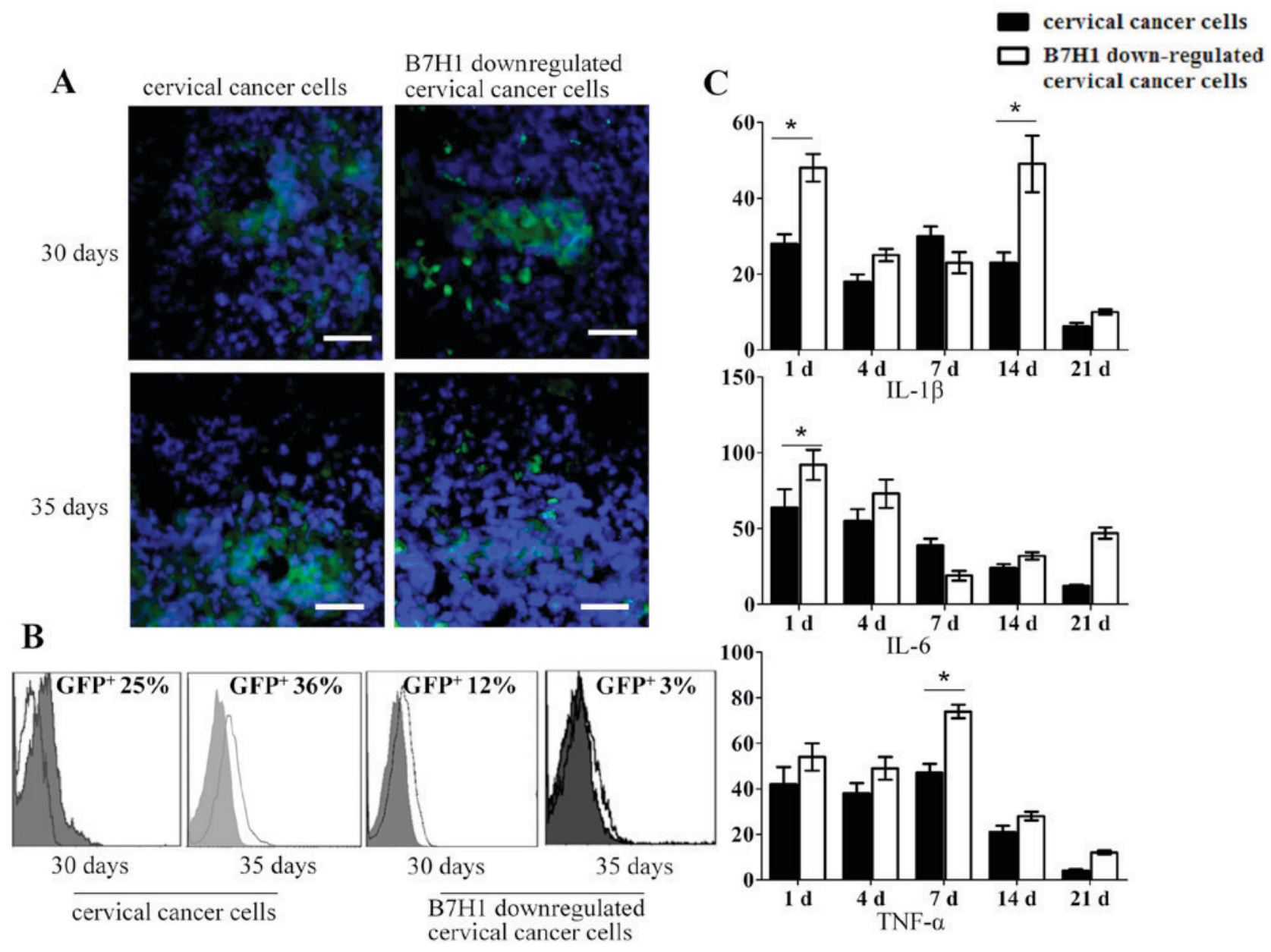

Figure 4. B7-H1 may aid the evasion of tumors from the immune system. (A) Immunofluorescence analysis of the presence of GFP-positive cells in cervical cancer cells and B7-H1 downregulated cervical cancer cells after 30 and 35 days' injection in mice. Scale bar, $40 \mu \mathrm{m}$. (B) Flow cytometry of GFP-positive cells from cervical cancer cell and B7-H1 downregulated cervical cancer cell-formed cervical cancer tissues after cell injection into BALB/c nude mice for 30 and 35 days, respectively (magnification, $x 10$ ). (C) Reverse transcription-quantitative polymerase chain reaction analysis of IL-1 $\beta$, IL- 6 and TNF- $\alpha$ mRNA levels on days 1, 4, 7, 14 and 21 in the cervical cancer cells and B7-H1 downregulated cervical cancer cells group. The data are presented as the mean \pm standard deviation of three independent experiments. Analysis was performed with GraphPad Prism; * $\mathrm{P}<0.05$. B7-H, B7 homolog; IFN, interferon; IL, interleukin; TGF, transforming growth factor; GFP, green fluorescent protein; TNF, tumor necrosis factor.

\section{Discussion}

Cervical cancer is the most common malignant tumor detected in the female genital tract and its incidence rate has recently increased $(1,2)$. T cell immunity serves a vital role in the recognition and killing of tumor cells, as well as the inhibition of tumor growth and proliferation (27). The occurrence and development of cervical cancer is associated with the low immune function of the local microenvironment of the host, particularly the immune function of T cells (28). B7-H1, also known as programmed death ligand, is a member of the B7 family. The binding of B7-H1 (programmed death-ligand 1) to its receptor, programmed cell death protein 1 , can inhibit the proliferation of $\mathrm{T}$ cells and the secretion of some cytokines in vitro (29-31). B7-H1 acts as a negative co-stimulatory molecule in the process of $\mathrm{T}$ cell activation and may serve a major role in suppressing the immune system during certain events including pregnancy, tissue allografts (32), autoimmune disease (33) and other disease states such as hepatitis (34). A number of studies have detected elevated B7-H1 expression in numerous tumors and cancer cell lines, including non-small cell lung cancer (35), melanoma (36), colon cancer (37), renal cell carcinoma (38), ovarian cancer (39), pancreatic cancer (40), gastric cancer (41) and breast cancer (42).

The present study found that B7-H1 was highly expressed in cervical cancer cells and also in cervical cancer tissue, whereas normal cervical epithelium and the paracancerous tissue did not express B7-H1. Furthermore, it was demonstrated that when B7-H1 was downregulated via its specific blocking antibody and siRNA, it significantly inhibited the suppression of T lymphocytes. When co-cultured with B7-H1 downregulated cervical cancer cells, the levels of the cytokines IFN- $\gamma$, IL-10 and TGF- $\beta 1$ secreted by $\mathrm{T}$ cells differed significantly compared with cervical cancer cells. Cervical cancer cells can form tumors more easily than B7-H1 downregulated cervical cancer cells in vivo and elicit a more moderate immune response. Therefore, $\mathrm{B} 7-\mathrm{H} 1$ is able to mediate the immune escape of cervical cancer cells.

It has been demonstrated that when B7-H1 is blocked effectively in vivo, the lethality of immune cells in cancer tissue can be strengthened (43) and this could be potentially applied to treat B7-H1-positive tumors. Thus, the immunoregulatory 
function of B7-H1 holds important clinical value for treatment and for the molecular targeted therapy of gynecological malignant tumors.

In conclusion, findings of the present study indicated that B7-H1 mediated the inhibition of T lymphocyte activation of cervical cancer cells. When B7-H1 was downregulated, the cell viability of B7-H1 downregulated cervical cancer cells did not change compared with cervical cancer cells, whereas the soluble factors that are secreted by $\mathrm{T}$ cells changed between cervical cancer cells and B7-H1 downregulated cervical cancer cells. In an in vivo animal model, injected B7-H1 downregulated cervical cancer cells exhibited a potent immune response, whereas cervical cancer cells provoked the weak immune response. The findings suggest that B7-H1 mediated the low immunogenicity of cervical cancer and evaded attack from the immune system.

\section{Acknowledgements}

Funding for the present study was provided by Special Funds for Industrial Technology Innovation of Suzhou (grant no. SYS201567), Technical Specification for Diagnosis and Treatment of Clinical Diseases of Suzhou (grant no. LCZX201410), Clinical Medical Centers of Suzhou (grant no. SZZX201505) and Maternal and Child Health Program of Jiangsu Province (grant nos. F201410 and F201680).

\section{References}

1. Hammes LS, Tekmal RR, Naud P, Edelweiss MI, Kirma N, Valente PT, Syrjänen KJ and Cunha-Filho JS: Macrophages, inflammation and risk of cervical intraepithelial neoplasia (CIN) progression-clinicopathological correlation. Gynecol Oncol 105: $157-165,2007$.

2. Hu SY, Zheng RS, Zhao FH, Zhang SW, Chen WQ and Qiao YL: Trend analysis of cervical cancer incidence and mortality rates in Chinese women during 1989-2008. Zhongguo Yi Xue Ke Xue Yuan Xue Bao 36: 119-125, 2014 (In Chinese).

3. Wu YY, Liang MR, Li LY and Zeng SY: Analysis of 4223 hospitalized patients with cervical cancer during 1990-2007. Zhonghua Fu Chan Ke Za Zhi 43: 433-436, 2008 (In Chinese).

4. Human papillomavirus testing for triage of women with cytologic evidence of low-grade squamous intraepithelial lesions: Baseline data from a randomized trial. The Atypical Squamous Cells of Undetermined Significance/Low-Grade Squamous Intraepithelial Lesions Triage Study (ALTS) Group. J Natl Cancer Inst 92: 397-402, 2000.

5. Luo XM, Song L, Wu JL, Liu Y, Di JL, Song B, Zheng RM and Ma L: Analysis of the reported data of national rural cervical cancer screening project from 2012 to 2013 , China. Zhonghua Yu Fang Yi Xue Za Zhi 50: 346-350, 2016 (In Chinese).

6. Anisimov VN: Syndrome of accelerated aging induced by carcinogenic environmental factors. Ross Fiziol Zh Im I M Sechenova 96: 817-833, 2010 (In Russian).

7. Stroh EL, Besa PC, Cox JD, Fuller LM and Cabanillas FF: Treatment of patients with lymphomas of the uterus or cervix with combination chemotherapy and radiation therapy. Cancer 75: 2392-2399, 1995.

8. Park HJ, Chang AR, Seo Y, Cho CK, Jang WI, Kim MS and Choi C: Stereotactic body radiotherapy for recurrent or oligometastatic uterine cervix cancer: A cooperative study of the Korean radiation oncology group (KROG 14-11). Anticancer Res 35: 5103-5110, 2015.

9. Kim KH, Dishongh R, Santin AD, Cannon MJ, Bellone S and Nakagawa M: Recognition of a cervical cancer derived tumor cell line by a human papillomavirus type 16 E6 52-61-specific CD8 T cell clone. Cancer Immun 6: 9, 2006.

10. Dong H, Strome SE, Salomao DR, Tamura H, Hirano F, Flies DB, Roche PC, Lu J, Zhu G, Tamada K, et al: Tumor-associated B7-H1 promotes T-cell apoptosis: A potential mechanism of immune evasion. Nat Med 8: 793-800, 2002.
11. Chew V, Toh HC and Abastado JP: Immune microenvironment in tumor progression: Characteristics and challenges for therapy. J Oncol 2012: 608406, 2012.

12. Ghebeh H, Mohammed S, Al-Omair A, Qattan A, Lehe C, Al-Qudaihi G, Elkum N, Alshabanah M, Bin Amer S, Tulbah A, et al: The B7-1 (PD-L1) T lymphocyte-inhibitory molecule is expressed in breast cancer patients with infiltrating ductal carcinoma: Correlation with important high-risk prognostic factors. Neoplasia 8: 190-198, 2006.

13. Hamanishi J, Mandai M, Iwasaki M, Okazaki T, Tanaka Y, Yamaguchi K, Higuchi T, Yagi H, Takakura K, Minato N, et al: Programmed cell death 1 ligand 1 and tumor-infiltrating CD8 ${ }^{+}$ T lymphocytes are prognostic factors of human ovarian cancer. Proc Natl Acad Sci USA 104: 3360-3365, 2007.

14. Ohigashi Y, Sho M, Yamada Y, Tsurui Y, Hamada K, Ikeda N, Mizuno T, Yoriki R, Kashizuka H, Yane K, et al: Clinical significance of programmed death-1 ligand-1 and programmed death-1 ligand-2 expression in human esophageal cancer. Clin Cancer Res 11: 2947-2953, 2005.

15. Thompson RH, Kuntz SM, Leibovich BC, Dong H, Lohse CM, Webster WS, Sengupta S, Frank I, Parker AS, Zincke H, et al: Tumor B7-1 is associated with poor prognosis in renal cell carcinoma patients with long-term follow-up. Cancer Res 66: 3381-3385, 2006.

16. Wu C, Zhu Y, Jiang J, Zhao J, Zhang XG and Xu N: Immunohistochemical localization of programmed death-1 ligand-1 (PD-L1) in gastric carcinoma and its clinical significance. Acta Histochem 108: 19-24, 2006.

17. Wang X, Wang T, Xu M, Xiao L, Luo Y, Huang W, Zhang Y and Geng W: B7-H4 overexpression impairs the immune response of $\mathrm{T}$ cells in human cervical carcinomas. Hum Immunol 75: 1203-1209, 2014.

18. Han S, Li Y, Zhang J, Liu L, Chen Q, Qian Q, Li S and Zhang Y: Roles of immune inhibitory molecule B7-H4 in cervical cancer. Oncol Rep 37: 2308-2316, 2017.

19. Liu W, Shibata K, Koya Y, Kajiyama H, Senga T, Yamashita M and Kikkawa F: B7-H4 overexpression correlates with a poor prognosis for cervical cancer patients. Mol Clin Oncol 2: 219-225, 2014.

20. Zhang W, He W, Shi Y, Gu H, Li M, Liu Z, Feng Y, Zheng N, Xie $\mathrm{C}$ and Zhang Y: High expression of KIF20A Is associated with poor overall survival and tumor progression in Early-stage cervical squamous cell carcinoma. PLoS One 11: e0167449, 2016.

21. Livak KJ and Schmittgen TD: Analysis of relative gene expression data using real-time quantitative PCR and the 2(-Delta Delta C(T)) method. Methods 25: 402-408, 2001.

22. Pilz GA, Braun J, Ulrich C, Felka T, Warstat K, Ruh M, Schewe B, Abele H, Larbi A and Aicher WK: Human mesenchymal stromal cells express CD14 cross-reactive epitopes. Cytometry A 79: 635-645, 2011.

23. Herzenberg LA, Tung J, Moore WA, Herzenberg LA and Parks DR: Interpreting flow cytometry data: A guide for the perplexed. Nat Immunol 7: 681-685, 2006.

24. Pinto AE, Areia F, Pereira T, Cardoso P, Aparício M, Silva GL, Ferreira MC and André S: Clinical relevance of the reappraisal of negative hormone receptor expression in breast cancer. Springerplus 2: 375, 2013.

25. Fei F, Yu Y, Schmitt A, Rojewski MT, Chen B, Greiner J, Götz M, Guillaume P, Döhner H, Bunjes D and Schmitt M: Dasatinib exerts an immunosuppressive effect on $\mathrm{CD} 8^{+} \mathrm{T}$ cells specific for viral and leukemia antigens. Exp Hematol 36: 1297-1308, 2008.

26. Zou Q, Jin J, Xiao Y, Zhou X, Hu H, Cheng X, Kazimi N, Ullrich SE and Sun SC: T Cell Intrinsic USP15 deficiency promotes excessive IFN- $\gamma$ production and an immunosuppressive tumor microenvironment in MCA-induced fibrosarcoma. Cell Rep 13: 2470-2479, 2015.

27. Yan M, Himoudi N, Pule M, Sebire N, Poon E, Blair A, Williams O and Anderson J: Development of cellular immune responses against PAX5, a novel target for cancer immunotherapy. Cancer Res 68: 8058-8065, 2008.

28. Shen YM, He X, Deng HX, Xie YP, Wang CT, Wei YQ and Zhao X: Overexpression of the hBiot 2 gene is associated with development of human cervical cancer. Oncol Rep 25: 75-80, 2011.

29. Riella LV, Paterson AM, Sharpe AH and Chandraker A: Role of the PD-1 pathway in the immune response. Am J Transplant 12: 2575-2587, 2012.

30. Guo Z, Wang H, Meng F, Li J and Zhang S: Combined trabectedin and anti-PD1 antibody produces a synergistic antitumor effect in a murine model of ovarian cancer. J Transl Med 13: 247, 2015. 
31. Weinstock M and McDermott DF: Emerging role for novel immunotherapy agents in metastatic renal cell carcinoma: From bench to bedside. Am Soc Clin Oncol Educ Book 2015: e291-e297, 2015.

32. Wang YT, Zhao XY, Zhao XS, Xu LP, Zhang XH, Wang Y, Liu KY, Chang YJ and Huang XJ: The impact of donor characteristics on the immune cell composition of mixture allografts of granulocyte-colony-stimulating factor-mobilized marrow harvests and peripheral blood harvests. Transfusion 55: 2874-2881, 2015.

33. Wilson CL, Murphy LB, Leslie J, Kendrick S, French J, Fox CR, Sheerin NS, Fisher A, Robinson JH, Tiniakos DG, et al: Ubiquitin C-terminal hydrolase 1 (UCHL1) A novel functional marker for liver myofibroblasts and a therapeutic target in chronic liver disease. J Hepatol 63: 1421-1428, 2015.

34. Xie ZY, Chen YW, Fu XL, Yang CY and Wu YZ: Expression of B7-H1 on peripheral blood mononuclear cells from chronic hepatitis B patients. Nan Fang Yi Ke Da Xue Xue Bao 27: 1635-1637, 2007 (In Chinese)

35. Jin $X$ and Xie C: TH-AB-BRB-04: Dosimetric and clinical benefits of conformal radiotherapy plus volumetric modulated arc therapy in the treatment of non-small cell lung cancer. Med Phys 42: 3704, 2015.

36. Harshman LC, Choueiri TK, Drake C and Stephen Hodi F Jr: Subverting the B7-H1/PD-1 pathway in advanced melanoma and kidney cancer. Cancer J 20: 272-280, 2014.

37. Shi SJ, Wang LJ, Wang GD, Guo ZY, Wei M, Meng YL, Yang AG and Wen WH: B7-H1 expression is associated with poor prognosis in colorectal carcinoma and regulates the proliferation and invasion of HCT116 colorectal cancer cells. PLoS One 8 e76012, 2013.
38. Thompson RH, Gillett MD, Cheville JC, Lohse CM, Dong H, Webster WS, Krejci KG, Lobo JR, Sengupta S, Chen L, et al: Costimulatory B7-H1 in renal cell carcinoma patients: Indicator of tumor aggressiveness and potential therapeutic target. Proc Natl Acad Sci USA 101: 17174-17179, 2004.

39. Pfankuchen DB, Stölting DP, Schlesinger M, Royer HD and Bendas G: Low molecular weight heparin tinzaparin antagonizes cisplatin resistance of ovarian cancer cells. Biochem Pharmacol 97: 147-157, 2015.

40. Srivastava SK, Bhardwaj A, Arora S, Tyagi N, Singh S, Andrews J, McClellan S, Wang B and Singh AP: MicroRNA-345 induces apoptosis in pancreatic cancer cells through potentiation of caspase-dependent and -independent pathways. Br J Cancer 113: 660-668, 2015.

41. Karabulut M, Alis H, Afsar CU, Karabulut S, Kocatas A, Oguz H and Aykan NF: Serum neural precursor cell-expressed, developmentally down regulated 9 (NEDD9) level may have a prognostic role in patients with gastric cancer. Biomed Pharmacother 73: 140-146, 2015.

42. Chen Q, Fang X, Jiang C, Yao N and Fang X: Thrombospondin promoted anti-tumor of adenovirus-mediated calreticulin in breast cancer: Relationship with anti-CD47. Biomed Pharmacother 73: 109-115, 2015.

43. Mirza N, Duque MA, Dominguez AL, Schrum AG, Dong H and Lustgarten J: B7-H1 expression on old CD8+ T cells negatively regulates the activation of immune responses in aged animals. J Immunol 184: 5466-5474, 2010. 